\title{
RESUMO
}

\section{FOTOGRAFIA E OUTROS DESAFIOS DIGITAIS NAS PESQUISAS COM CRIANÇAS}

\section{PHOTOGRAPHY AND OTHER DIGITAL CHALLENGES INETHNOGRAPHIES WITHCHILDREN}

\section{FOTOGRAFÍA Y OTROS DESAFIOSS DIGITALES ENETNOGRAFíAS CON NINNOS}

Nesse artigo abordaremos algumas possibilidades de usos de fotografia, aplicativos digitais móveis e diarismo online no fazer etnográfico. Nossa pesquisa envolve especificamente crianças de terreiros brasileiros. No entatanto, pensamos que as reflexões trazidas interessem a qualquer pesquisador ou pesquisadora que esteja envolvido na etnografia com fotografia e, especialmente, na etnografia com crianças. A pesquisa foi realizada durante dois anos em dois terreiros de candomblé em Duque de Caxias, Rio de Janeiro.

\section{PALAVRAS-CHAVE}

Infância em Terreiros; Fotografia; Diarismo online; aplicativos em etnografia. 


\section{ABSTRACT}

In this article we will discuss some possibilities of uses of photography, mobile digital applications and online diarism in ethnographic making. Our research specifically involves children from Brazilian terreiros. However, we think that the reflections brought to the attention of any researcher who is involved in ethnography with photography and especially in the ethnography with children. The research was carried out during two years in two candomblé terreiros in Duque de Caxias, Rio de Janeiro.

\section{KEYWORDS}

Childhood in Terreiros. Photography. Online Diary. Applications in Ethnography.

\section{RESUMEN}

En este artículo discutiremos algunas posibilidades de usos de la fotografía, aplicaciones digitales móviles y diarismo en línea en la creación etnográfica. Nuestra investigación involucra específicamente a niños de terreiros brasileños. Sin embargo, creemos que las reflexiones llamaron la atención de cualquier investigador involucrado en la etnografía con fotografía y especialmente en la etnografía con niños. La investigación se llevó a cabo durante dos años en dos candomblé terreiros en Duque de Caxias, Río de Janeiro.

\section{PALABRAS CLAVE}

Infancia en Terreiros. Fotografía. Diario en línea. Aplicaciones en etnografía 


\section{INTRODUÇÃO: OGUM X BLACK}

Fotografia 1 - Willians Bendia Santos

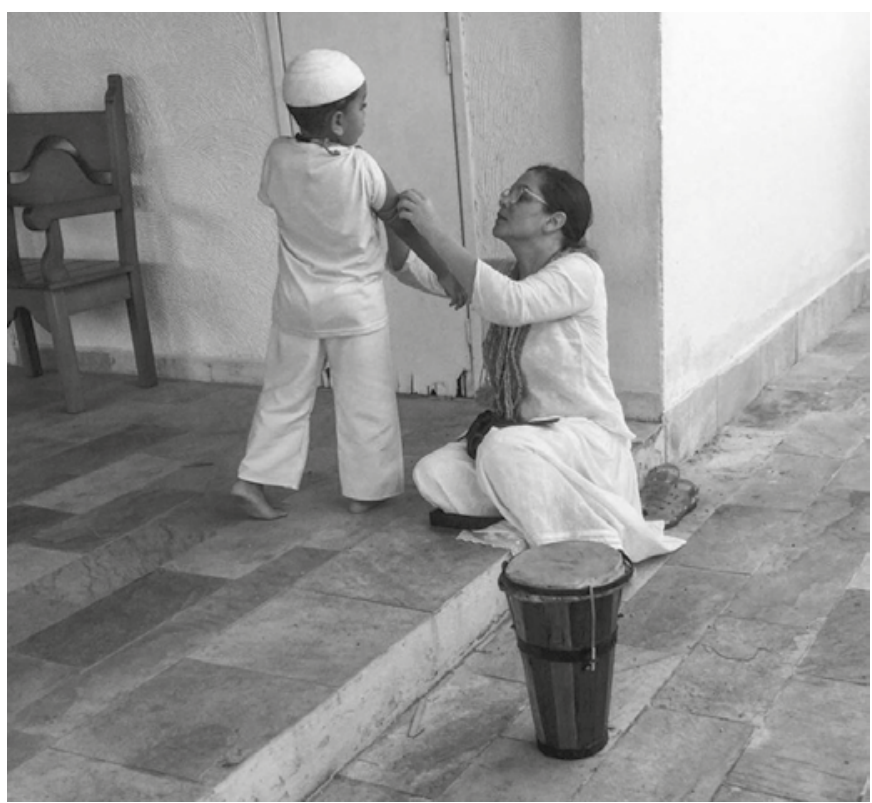

Fonte: A autora (2018).

-Ogum é o único que pode derrotar o Black.

- Quem é Black, Willians?

- Do Dragon Ball.

- Ah é? Por quê?

- Porque o Black pode ser imortal, mas Ogum é infinito.

O diálogo acima aconteceu entre mim e Willians Bendia Santos, de 6 anos, no dia $1^{\circ}$ de junho de 2018, no terreiro de candomblé, Ilê Axé Omi Lare Iyá Sagbá, em Duque de Caxias, onde somos, eu e ele, iniciados ${ }^{2}$. Eu estava sentada, esperando um ritual começar, quando o menino ofereceu o braço para que eu arrumasse seu contraegun (um artefato feito de um trançadinho de palha da costa). Enquanto arrumava, ele puxou a conversa. Um membro do terreiro fez a foto com o seu smartphone (Galaxy A 7), e comecei a anotar a conversa no Evernote, aplicativo instalado em meu smartphone (Iphone 6 plus).

2 Ser iniciado no candomblé é passar por um período de recolhimento, ritos e aprendizagens. Após esse período, a pessoa se torna um membro do terreiro, um filho ou filha da casa onde se iniciou. 
Em seguida, a foto me foi enviada por outro aplicativo (WhatsApp) e postei diálogo e foto, imediatamente, em minha página on-line de pesquisa no Facebook, atualmente chamada "Crianças de terreiro: fotoetnografia miúda”. A postagem teve: 600 curtidas, 96 comentários, 272 compartilhamentos e alcançou 51.364 pessoas.

Para Amaral, Santos e Santos (2019, p. 161), a globalização impulsinou transformações mundiais nas últimas décadas em especial, o desenvolvimento das tecnologias digitais em rede que provocam "mudanças radicais nos modos e meios de produção e de desenvolvimento em diferentes áreas das atividades humanas, em particular na educação”. As pesquisadoras enfatizam ser impossível uma desvinculação dos currículos praticados, nos cotidianos escolares, do cenário contemporâneo cibercultural, "em que processos de comunicação, sociabilidade, educação e aprendizagem se instituem, sob o risco de criarmos um fosso entre processos culturais e de aprendizagem" (AMARAL; SANTOS; SANTOS, 2019, p. 161).

Em nossa opinião, o mesmo cenário cibercultural modifica os modos de fazer pesquisa, incluindo maneiras de estar e etnografar o campo. Como, então, por exemplo, os aplicativos modificam a prática da etnografia? Quais as implicações de inovações como essas nos hábitos dos pesquisadores, sobretudo, os que utilizam fotografias na pesquisa? 0 objetivo desse artigo é partilhar como temos usado diversos e simultâneos aplicativos em nossas pesquisas e como fotografamos e comunicamos (ou compartilhamos) achados e processos.

Em nosso caso singular, pesquisamos com crianças de terreiros. No entanto, as reflexões trazidas podem colaborar com qualquer pesquisador ou pesquisadora que se interesse pelos mais variados temas de pesquisa e que desejem utilizar fotografias e aplicativos no fazer etnográfico. Embora tal reflexão nos acompanhe já há bastante tempo, neste texto específico, abordaremos os últimos dois anos $(2017,2018)$ e observações em dois terreiros, ambos em Duque de Caxias, na Baixada Fluminense.

Quase 100 anos separam a maneira de anotar no campo, como apresentamos aqui da maneira de anotar o campo, como encontramos em Malinowski, antropólogo polonês que viveu nas ilhas Trobriand entre 1915 e 1918. A essa época, a antropologia como ofício ainda não estava bem delineada, mas já ganhava alguma distância da chamada antropologia de gabinete, ou seja, estudos produzidos por pesquisadores que sequer tinham contato com o grupo estudado e elaboravam suas descrições a partir de relatos de terceiros, em geral, missionários ou administradores coloniais.

Chegássemos hoje àquelas ilhas, ao descer da lancha ou barco, tão logo pisássemos na areia já estaríamos à procura de um sinal de wi-fi e de uma tomada para carregar smarthphone e tablet, mesmo antes de buscar qualquer interlocutor de pesquisa.

Se pensarmos dispositivo como "uma organização de meios materiais e/ou intelectuais, fazendo parte de uma estratégia de conhecimento de um objeto" (ARDOINO, 2003, p. 80), entenderemos que Malinowski dispunha dos dele e nós, dos nossos. Se Malinowski usava seu bom e velho caderno de notas, lápis, caneta e máquina fotográfica analógica, hoje podemos usar os mesmos dispositivos, caderno, lápis, câmeras (analógicas se preferirmos) e mais um imenso número de aplicativos (apps) disponíveis em lojas on-line (Windows Store, Google Store, Apple Store). 
O termo "App" é uma abreviação de application, que significa "aplicativo" em português e pode ser oferecido em versão gratuita ou paga para ser executado diretamente em um ou mais sistemas operacionais móveis (Android, IOS, Windows Phone). Assim, os dispositivos digitais móveis assemelham-se cada vez mais aos computadores em termos de funcionalidade e recursos disponíveis. (SANTOS et al., 2006, p. 94).

Malinowski e outros tantos antropólogos passavam anos organizando, transcrevendo, interpretando, mediando suas notas de campo até que pudessem publicá-las em livros, artigos, capítulos. Etnógrafos também fazem isso hoje, já que a etnografia exige tempo no campo com sua inseparável e não dicotômica mediação teórica permanente. Era longo o tempo que separava esse diálogo vivido no campo de sua revelação quando Malinowski pesquisava.

Para Goldman (1998), a fama de Malinowski se deve justamente à sua capacidade de transformar o que chamou de "a carne e o sangue" da vida cotidiana por meio do trabalho de campo e, isso levou e sempre levará tempo. Para realizar bem essa transformação, Goldman vê como indispensável a elaboração de um bom diário etnográfico.

Atualmente, com a revolução provocada pelas tecnologias móveis conectadas às redes digitais, o tempo que separa o diálogo vivivo pode ser apenas o tempo gasto em fazer nota, foto ou filme (ou todos esses), editar e compartilhar nas redes sociais. Obviamente, isso depende do desejo do pesquisador, da relação deste com os aplicativos, com as redes sociais e da qualidade da conexão.

As mesmas tecnologias de hoje que possibilitam um compartilhamento imediato, inclusive de nossas anotações etnográficas, garantem também, pelo menos, duas coisas importantes: 1 - Um modo mais seguro de armazenar e proteger as notas de campo; 2 - A privacidade das anotações que não desejamos tornar públicas (ou que precisamos de mais cuidado até torna-las públicas). Pensemos no terror que seria, caso uma tempestade, naufrágio, incêndio ou qualquer outro acidente desse fim às notas de Malinowski, ou as de Evans-Pritchard, depois de três anos anotando a vida dos Azande?

Acredito que essas e outras questões possam interessar a todos e todas que estejam mergulhados e mergulhadas na desafiadora tarefa de anotar o campo de pesquisa, seja qual for 0 seu campo de pesquisa. Interessam muito a mim que etnografo no que chamo de "Estudos com crianças de terreiros". 


\title{
2 “É DE CANTAR FOLHA QUE EU GOSTO”: OS ESTUDOS COM CRIANÇAS DE TERREIROS
}

\author{
Fotografia 1 - Mene Viana Cardoso
}



Fonte: A autora (2017).

A fala que dá título a essa parte de nosso artigo é de Mene Viana Cardoso, 3 anos (foto anterior), soprada no dia 5 de agosto de 2017. Havia um barco de três iniciados saindo naquela tarde no Ilê Axé Omi Lare lyá Sagbá, um terreiro de candomblé, em Santa Cruz da Serra, Duque de Caxias, na Baixada Fluminense. Um barco de iaôs é um conjunto de pessoas que se iniciam ao mesmo tempo. Aliás, foi nesse terreiro que tanto Willians Bendia, Mene Viana e eu fomos iniciados. Sendo assim, me dividia entre as funções de filha de santo e as funções de pesquisadora no campo, o que nunca é fácil.

Saudei o portão, o axé central da casa, os atabaques, os orixás. Tomei bênção ao pai de santo, aos mais velhos, aos mais novos. Lavei louça, varri o barracão, busquei meu lugar na fila do xirê (a cerimônia pública em que dançamos em torno dos elementos centrais do terreiro sempre rodando no sentido anti-horário). Xirê cantado e dançado completo, retiro meu smartphone da cintura, pego a câmera fotográfica que sempre me aguarda silenciosa bem rente ao chão externo do barracão. Intervalo. Onde está Mene?

- Eu sei cantar a folha do Babá todinha. A minha folha eu também sei e a folha da minha mãe eu também sei. A sua folha, você sabe? É de cantar folha que eu gosto. Canta a sua. Mene cantou as folhas que sabia e, respondendo ao que ela perguntou, cantei a minha. Jagun (2017) lembra que a folha (ewé) é um dos principais elementos da natureza utilizados em ritos do candomblé, desde os iniciáticos aos fúnebres. Por isso, o provérbio iorubá: Kò sí ewé, kòsí Òrìa (Sem folha não há orixá). 0 elo com a folha (e com outros elementos) é a boca, que sopra, mastiga, cospe e pronuncia palavra. Mas não se trata de palavra desabitada, já que conduz o Emí, o hálito sagrado na tradição oral. A palavra é Emí, é fala, verbo atuante.

Os terreiros, entre eles os terreiros de candomblé, preservaram e ressignificaram modos de vida trazidos do continente africano durante a escravização. Conhecimentos sofisticados atravessaram o 
Atlântico e foram mantidos e reinventados nesses espaçostempos ${ }^{3}$. Uma das experiências protegidas é o complexo compartilhamento do conhecimento pela oralidade, muito embora o uso da escrita não seja visto como contraditório.

De geração após geração a cultura iorubá, entre outras culturas do continente africano, é perpetuada nos candomblés, por meio, entre outras coisas, dos itán (histórias), da invocação dos Deuses pelos orin (cânticos sagrados), das aduras (súplicas e orações), dos òwe (provérbios), dos oríki(louvações), dos ofós, os encantamentos de elementos como as folhas, que Mene sabe cantar e encantar. No nosso terreiro, meu e de Mene, cada uma e cada um de nós, durante a iniciação, tem sua folha escolhida, em ritual específico e não público.

Em todas as nossas demais “obrigações” (os ciclos periódicos que completam a iniciação), precisaremos cantá-la. Em alguns outros rituais da casa, também. É por isso que Mene diz orgulhosa que sabe cantar a folha do Babá (nosso pai de santo), a folha da mãe dela (sua mãe biológica) e sua própria folha. É por isso que, testando meu conhecimento, ela também me pergunta se eu sei cantar a minha folha.

Nada nesse contínuo ensinaraprenderensinar do qual falei está apartado. Todos esses elementos se fabricam e se misturam, feito quando a gente coloca a farinha de milho branco na panela para cozinhar e preparar o acaçá, uma das mais importantes comidas rituais no candomblé. A água procura a farinha, a farinha procura a água e ambas vão sendo misturadas bem devagar até formar um creme que depois será cuidadosamente envolvido em uma folha de bananeira. Um pouco como quando aprendemosensinamos ou quando no campo pesquisamos envolvidos por empirias, questões, teorias.

É então a palavrahálito que procura e une a boca ao ouvido das pessoas, dos elementos, dos deuses, que empodera e distribui. Ou enfraquece, já que a depender da palavra, esta também desarmoniza e destrói. $O$ escritor malinês Amadou Hampâté Bâ (2010, p.174), ao recordar um poema ritual de seu país, explicita melhor: "A fala é divinamente exata, convém ser exato para com ela. A língua que falsifica a palavra vicia o sangue daquele que mente".

0 que temos chamado de Estudos com crianças de terreiros é um processo aberto e em construção, especialmente no que diz respeito ao nosso modo de fazer pesquisa. Nascem na interseccionalidade de três grandes negações: a primeira origina-se de concepções sociológicas que negam a criança como sujeito de conhecimento e participação social, portanto silenciando-as. A segunda foi (e continua sendo) praticada pelo projeto colonial racista que submeteu corpos, conhecimentos e memórias negando a vida de africanos e africanas, homens, mulheres e crianças, arrancados e arrancadas de seu continente, escravizados, dispersados. A terceira herança hegemônica foi deixada pelo modo dominante com o qual a modernidade "via" os cotidianos, tidos como lugar de saberes menores.

Em um caminho original, como já dissemos, nosso grupo de pesquisa, Kékeré (pequeno em iorubá) desenvolve estudos que contrariam essa tripla negação para afirmar, também na interseccionalidade que, justamente àquelas consideradas insignificantes, incompletas, não confiáveis (as crianças), os conhecimentos e culturas igualmente considerados inferiores (tradições afrodiaspóricas), incluindo os terreiros de religiões afrodescendentes e os espaçostempos considerados

3 Alves explica que usa esses termos juntos para indicar que as pesquisas nos/dos/com os cotidianos pretendem ir além do que vê como dicotomias e limites herdados das ciências modernas. Particularmente, em nossos textos, fazemos essa opção em apenas algumas expressões, este é um caso. Também optamos por dizer pesquisas com os cotidianos apenas. 
também menores (cotidianos) são fundamentos vitais para compreender a sociedade brasileira, bem como, desestabilizar suas lógicas coloniais profundas que, seguramente, afetam as crianças.

Por questionarem a visão da criança como incompleta e sem voz, os Estudos da Infância são fundamentais para contrariar a primeira negação e afirmar, também em nossas pesquisas, as crianças como sujeitos ativos de si e do mundo. Para contrariar a segunda negação, nos valemos dos Estudos afro-brasileiros pesquisas históricas, sociológicas, antropológicas que analisam a presença africana e afrodescendente no Brasil, incluindo os estudos de religiões de matriz africana. Porque afirmamos os cotidianos como espaçostempos de criação, culturas, solidariedade e invenção, os chamados Estudos com os Cotidianos nos ajudam a contrariar a terceira negação.

Chamamos o que fazemos de Reparar Miúdo e Narrar Kékeré, porque percebemos as crianças como sujeitos de si e do mundo e como interlocutores prioritários de nossas pesquisas. Tecemos nossas narrativas com as narrativas das crianças de terreiros. A fotografia tem sido um caminho fundamental no qual sentimos e comunicamos o mundo em que vivemos. Também nesse caminho, as crianças são os principais sujeitos e interlocutores das imagens que produzimos com elas. Por ser assim, chamamos nossa etnografia de Fotoetnografia Miúda, mas ela é bem mais que isso.

\section{NOTAS SOBRE FOTOGRAFIA E CANDOMBLÉ}

Fotografia 2 - Yasmin Ferreira

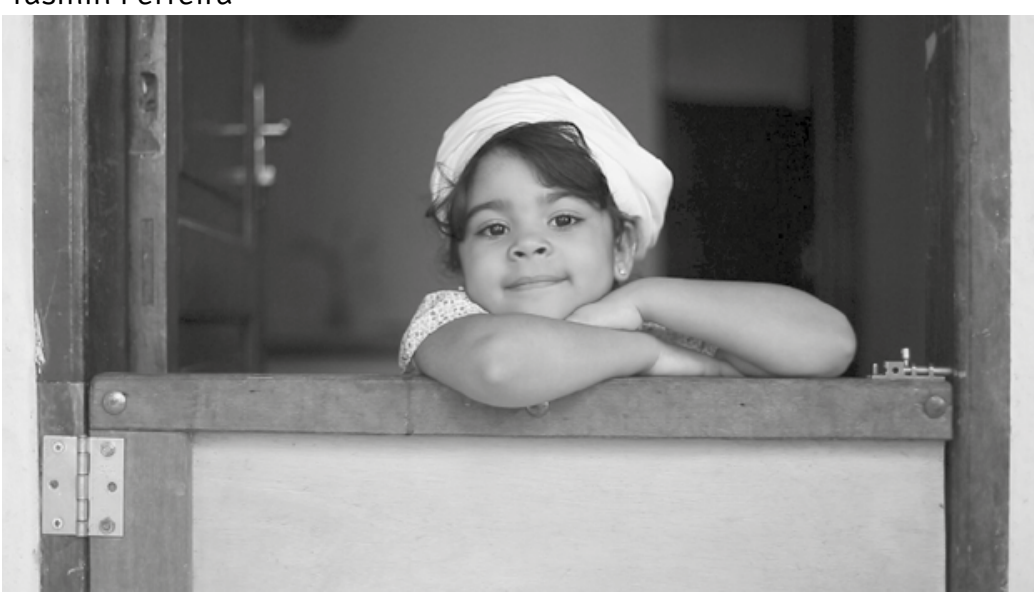

Fonte: A autora (2016).

"O terreiro é o ilê, uma casa que mora dentro da gente e a gente mora dentro dessa casa que mora dentro da gente" 
A fala que abre este texto, destacada na epígrafe anterior, é de Yasmin Ferreira, última filha de santo iniciada, aos 3 anos, por lyá Omindarewá, Iyalorixá do Ilê Axé Atará Magba, em Santa Cruz da Serra, Rio de Janeiro, falecida em 16 de janeiro de 2016. Yasmin (também na foto anterior) diz que o terreiro é o ilê (casa), em ioruba. Depois, Yasmin localiza essa casa dentro de seu próprio corpo e dentro dessa casa que ela levou para dentro de si, a menina se coloca e habita.

Mais do que traduções, são dobras e desdobramentos de sentidos. Dobras e desdobramentos provocam deslocamentos da superfície ao fundo e acontecem sempre que prestamos atenção ao que crianças comunicam. Fiz essa fotografia de Yasmin no dia 16 de outubro de 2016.

Comecei a fotografar e a conversar com crianças de terreiros na década de 1990 . Publiquei matéria sobre o tema em 1992, no jornal O Dia. Primeiro, então, como jornalista e depois como pesquisadora, interessava-me partilhar de seus conhecimentos. Interessava-me, por exemplo, como criavam enquanto aprendiam e ensinavam o próprio idioma preservado nas casas de santo, ou enquanto cuidavam dos Orixás, tocavam atabaques, cantavam e a dançavam para os Orixás. Enquanto recebiam os Orixás em seus próprios corpos.

Eu ainda não sabia, mas ao usar as fotografias ampliadas de crianças, trazendo seus nomes e seus depoimentos, abordava de maneira inédita uma área inteira e um campo específico. Quando digo área, me refiro à antropologia reforçando o que disse Hirschfeld, em artigo publicado na revista American Anthropologist, em 2002, para quem, apesar de alguns avanços, as crianças ainda são muito desprezadas nas pesquisas antropológicas, consideradas primitivas e de informações nada confiáveis para as etnografias.

Além disso, Hirschfeld acredita que, em nossa sociedade, existe uma superestimação da contribuição dos adultos para a cultura e, em contrapartida, uma subestimação das contribuições das crianças, esses seriam alguns motivos do pouco interesse da área nas pesquisas sobre crianças. Quando digo campo, me refiro a um campo singular de estudos que, justamente por sua singularidade, poderia já, há muito, ter contribuído para a diminuição da invisibilidade das crianças nas pesquisas.

Trata-se das pesquisas sobre Candomblé. Mas não. Nem mesmo os pesquisadores e fotógrafos clássicos de candomblé interessaram-se em pesquisar ou fotografar crianças de candomblé. Como não poderia deixar de ser, a justificativa que encontro para a negligência do campo é a mesma que Hirschfeld encontrou para a área das ciências sociais como um todo.

No meu caso específico, desde que publiquei a matéria com crianças de candomblé em, 1992, nunca mais saí dos terreiros e estaria neles não mais como jornalista "apenas", mas mantendo meus cadernos de campo, entrevistando e fotografando as crianças como protagonistas e principais interlocutores do que já se transformara em pesquisa na área da educação, usando a máquina fotográfica como um "bloco de notas" (tomando emprestado a expressão usada por Bresson), ou seja, fazendo etnografia, ainda que não fosse antropóloga.

Etnografia que tem na fotografia seu principal fundamento é Fotoetnografia e por ter as crianças como protagonistas e principais interlocutores, chamo de Fotoetnografia miúda. Para o que faço, a palavra miúdo sempre virá de Kékeré (pequeno, miúdo em iorubá), nome, inclusive, com o qual batizei o grupo de pesquisa que coordeno na Universidade do Estado do Rio de Janeiro (UERJ).

Qualquer pesquisador, cujo tema e questões seja o candomblé, conhece o trabalho de Pierre Verger, ainda que não fotografe. Se o fundamento da pesquisa é a fotografia, o trabalho de Verger é referência e inspi- 
ração. Contudo, notei uma ausência nele. Por óbvio não nos referimos aqui ao extraordinário e incomparável talento artístico de Verger, mas sim, à sua prática de fazer texto e fotos se completarem na pesquisa.

Durante muito tempo li os textos de Verger. Seu trabalho minucioso em descrever os cultos afro-brasileiros, seu esforço incansável de aproximar Brasil e África, em especial, as culturas iorubás foram e são fundamentais. Do mesmo modo, observei com amor suas fotos, demorando-me nos detalhes. Vendo e revendo, sempre descobrindo coisas novas. Tudo importava nas pesquisas de Verger e essa importância vinha do que, mais tarde, o pesquisador Jérôme Souty chamou de "tríptico", ou seja, as fontes visuais, textuais e orais, suas três comparsas.

De tanto olhar as fotografias de Verger, percebi uma ausência (só sentimos falta daquilo que procuramos). 0 fotógrafo francês até chegou a fotografar algumas vezes crianças nos cultos que tanto amou, seja no Brasil, África ou Cuba. A questão que constatamos é que as crianças, tanto em situações de culto nesses países ou nos cotidianos domésticos, não mereceram mais que poucas legendas de Verger (se muito!) quanto mais um estudo aprofundado textual ou imagético etnográfico.

Em seu extraordinário livro Notas sobre o culto dos Orixás e Voduns, cuja primeira edição foi em 1999, nas páginas 25 e 26 temos duas imagens comparativas, a primeira no Brasil e a segunda em África. Em ambas, podemos ver crianças tocando atabaques em meio aos adultos, mas a legenda diz apenas: "Três atabaques no Brasil... semelhantes a três atabaques na África". Por esses tempos, Verger estava muito preocupado em encontrar semelhanças nos cultos entre os dois países e só enxerga isso nos atabaques. Não é uma crítica, são os olhos de Verger e como liam o mundo. Na verdade, como a antropologia elegia e lia suas questões de pesquisa, inclusive imageticamente.

Publicada em 1951, na revista 0 Cruzeiro, a reportagem As Noivas dos Deuses Sanguinários, cria um verdadeiro paradigma no mundo da fotografia dos candomblés e aumenta as dificuldades para os fotógrafos e fotógrafas do tema. 0 ano era 1951. O cenário montado era a vaidade editorial. De um lado, a revista francesa Paris Match saiu na frente publicando Les possédées de Bahia.

Para não ficar atrás, no mesmo ano, a revista brasileira reage e publica a reportagem: As noivas dos deuses sanguinários, com 38 fotografias de um ritual de iniciação, em um terreiro em Salvador. José Medeiros foi o fotógrafo. Arlindo Silva, o repórter. Mãe Riso da Plataforma e suas três iaôs (filhas de santo) se tornaram as "personagens". 0 assunto, não se enganem, não era o candomblé, mas sim o preconceito contra uma tradição exotizada pelas duas publicações, que resultou no aumento da perseguição ao culto.

Seis anos após a publicação da reportagem, José Medeiros lança, em 1957, seu belo livro Candomblé. As 38 fotos de sua reportagem também estão lá, com mais outras 22 imagens, sem os títulos exóticos, sensacionalistas, apenas as fotos. Na página 54 temos a seguinte legenda: "Rum, Rumpi e Lé, os três atabaques empregados na marcação do ritmo do candomblé”. Atrás dos atabaques estão três crianças tocando os instrumentos. Tal como Verger, Medeiros não lhes deu a menor atenção.

A reportagem provocou sim furor no meio religioso e muita fantasia também. Hoje, graças a fundamental pesquisa de Fernando Tacca, sabe-se que Mãe Riso não foi assassinada por ter permitido a reportagem (pelo contrário, viveu muito bem com duas casas de santo abertas até o fim de seus dias). Sabe-se também que tampouco a iniciação das iaôs fotografada foi anulada, como se divulgou à época.

Exageros à parte em torno do caso, sabemos que a fotografia nos terreiros de candomblé é sim um assunto polêmico e encarado de maneiras distintas a depender da casa e da liderança dessa casa. A 
internet e as redes sociais parecem ter superado tabus, mas a ética não pode deixar de ser discutida. Tenho guardado a seguinte regra para mim ao longo dos anos de pesquisa: o Pai de Santo ou a Mãe de Santo deixou? Agradeço e fotografo. Não permitiu? Agradeço da mesma forma e não fotografo.

Eles e elas são os responsáveis espirituais dos terreiros, autorizam a entrada do pesquisador e o uso ou não da fotografia que, mesmo autorizada, pode ter restrições. Há casas, por exemplo, em que posso fotografar tudo, menos os Orixás, ou os Eguns (espíritos dos mortos). Há casas em que posso fotografar qualquer coisa pública, inclusive a presença dos Orixás. Nessas, as restrições se limitam aos rituais privados. Há casas em que posso fotografar rituais privados com exceção de alguns cuja interdição é definida pelo sacerdote ou sacerdotisa. Obedeço sem negociar e agradeço.

0 candomblé é uma religião de awo (segredo, mistério). Em muitos casos, a fotografia é vista como uma profanação desse segredo e a proibição será definitiva. Outras lideranças, no entanto, se preocupam com os usos públicos e com a circulação das fotografias. Por outro lado, há quem aposte na fotografia como afirmação identitária, daí a proliferação de todo tipo de foto, incluindo selfies, de candomblecistas e umbantistas com roupas tradicionais nos cotidianos dos terreiros e, até mesmo, fotos dos Orixás incorporados e cerimônias mais fechadas.

0 candomblé não é uma religião centralizada. Cada casa define a respeito do funcionamento da própria casa e de seus ritos, em geral, ligados à uma casa matriz. Isso também se aplica para a delicada decisão sobre fotografias que continua sendo responsabilidades do diálogo entre pais, mães de santo e seus oráculos.

Já para nós, fotógrafos e fotógrafas, há um sem fim de cuidados fundamentais, em especial, quando crianças são o centro de nosso olhar. E é sobre isso que continuaremos falando, incluindo a delicada (e fundamental) questão da autorização.

\section{FOTOETNOGRAFIA MIÚDA}

Fotografia 3 - Mikaela e Odin, no lle Axé Omi Lare lya, Sagbá, em Duque de Caxias

Fonte: A autora.

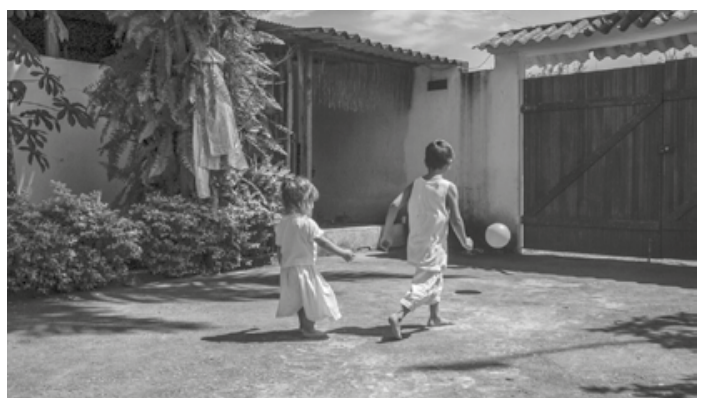

Macedo (2014), em diálogo com Bakhtin (2003), resgata o entendimento de ato como agir humano, ação situada, a que é atribuído ativamente um sentido no momento mesmo em que é realizada. 
Com o mesmo autor russo, Macedo compartilha a ideia de ato como o elemento que realiza a potência que o originou, destacando o processo como transformação constitutiva da potência em ato. Vejo, respiro e sinto em retângulo fotográfico. Quando decido debruçar o olho esquerdo no pequeno retângulo fotográfico, fecho o olho direito. Escolho e excluo, componho e crio.

Não excluo as crianças historicamente excluídas das etnografias, incluindo as etnografias de terreiros. Pelo contrário, elas são cotidianamente incluídas porque reparar nas crianças de terreiros é ação imanente: política, ética, estética e epistemológica situada, atribuída de sentido, quando é realizada (e mesmo quando antes é imaginada e buscada). Fotografo em ato imanente miúdo, buscando o que foi desprezado em pesquisas, seja com câmeras profissionais, seja com smartphones.

O que chamo então de Fotoetnografia Miúda nasce com os Estudos com Crianças de Terreiros, com o qual vamos dialogando aqui. É uma etnografia feita com fotografias nos cotidianos das casas de santo, que têm as crianças como principais interlocutoras de diálogo e imagem. Em nosso caso é com crianças de terreiros, mas pode ser pensada para outras crianças de outros campos de pesquisa. Também não é metodologia. É nossa cosmopercepção do mundo e já explicaremos.

Embora sejam fundamentais, nunca foram só os olhos. Sempre achei que fotografava com o corpo inteiro por vários motivos. Sem flashes, por interdição e estética, quando usada, a velocidade baixa pede uma respiração delicada, o dedo leve. Olhos, ouvidos, respiração, todos os sentidos acionados, envolvidos e conectados na Fotoetnografia Miúda. Essa combinação de sentidos não ensina apenas sobre fotografia.

Essa combinação de sentidos é própria da cultura dos povos iorubás e ouvimos isso da socióloga nigeriana Oyèrónké Oyewùmí (2019) 4 depois de muito praticar o que estamos apresentando até agora. Para esta pesquisadora, o termo cosmovisão, usado no Ocidente para resumir a lógica cultural de uma sociedade, capta o privilégio ocidental do visual. É eurocêntrico usá-lo para descrever culturas que podem privilegiar outros sentidos, diz ela. Já o termo cosmopercepção é uma maneira mais inclusiva de descrever a concepção de mundo por diferentes grupos culturais. É por isso que afirmamos: nossa fotoetnografia miúda não é apenas nossa metodologia e não diz de nós apenas como fotografamos. É, repito, nossa cosmopercepção de mundo.

É preciso dizer que essa fotografia em ato imanente miúdo, aciona minunciosamente diversas questões, muitas questões. 0 que entra no foco? Como compomos? Na maior parte de minhas fotografias procuro ou ficar no mesmo nível da criança fotografada ou abaixo dela. Não digo que nunca fiz o inverso, mas toda vez que fiz, em função de uma escolha estética, tinha consciência de que essa escolha estética estaria impregnada que questões éticas e políticas.

Também temos acionado a fotografia com crianças em terreiros no sentido do que Boaventura Sousa Santos (1996) chamou de imagens desestabilizadoras. Por isso, acrescento, penso as fotografias que fazemos como imagens descoloniais porque desestabilizam e desacostumam lugares acostumados na lógica dominante da colonialidade: racista, branca, cristã e adultocêntrica.

E autorização? Quem autoriza a participação da criança? seu nome? sua fotografia? São questões

4 OYEWÙMÍ, OYĖRÓNKÉ. Visualizing the Body: Western Theories and African Subjects in: OYEWÙMí, Oyèrónké. The invention of women: making an African sense of western gender discourses. Minneapolis: University of Minnesota Press, 1997, p. 1-30. Tradução para uso didático de WANDERSON FLOR DO NASCIMENTO. Disponível em: https://filosofia-africana.weebly.com/. Acesso em: 12/07/2019. 
que a educadora Sônia Kramer já abordava em artigo publicado em 2002, questionando que se a autorização quem dá é o adulto e não a criança, cabe indagar quem é o sujeito da pesquisa? Sim os pais devem ser os primeiros a autorizar a fotografia. A eles explicamos nossa pesquisa. Confeccionamos e, com eles compartilhamos, o Termo de Consentimento Livre e Esclarecido (TCLE) que devem assinar, como recomenda as Normas e Diretrizes Brasileiras que ordenam as pesquisas envolvendo seres humanos.

Mais recentemente, a pesquisadora Natália Fernandes afirmou que falar de ética na pesquisa com crianças não implica somente ter cuidados em como se planifica essa pesquisa, mas implica, sobretudo, atender aos modos como desencademos processos dialógicos e ponderados, de forma que se possa respeitá-las ontologicamente em sua alteridade.

Concordo com Fernandes e acrescento que, se a pesquisa envolve fotografia, esse respeito à alteridade da criança deve mover e guiar cotidianamente cada escolha fotográfica. Por isso, a criança também autoriza ou não autoriza a sua fotografia. As diretrizes citadas anteriormente recomendam, nesse caso, o Termo de Assentimento (TA) que deverá ser desenvolvido quando o participante da pesquisa for criança ou adolescente.

\section{ETNOGRAFANDO E COMUNICANDO A PESQUISA: CONSIDERAÇÕES FINAIS}

Voltemos à conversa com Willians, mencionada no início desse artigo. Como disse, para fazer a nota nessa situação de campo, usei especificamente o Evernote e o WhatsApp. O Evernote permite a criação de várias notas que podem ser organizadas em diferentes cadernos. É um aplicativo para dispositivos digitais móveis, também para computadores fixos (desktop), que permite a sincronização da sua conta, atualizando automaticamente conteúdos em todos os demais dispositivos onde estiver instalado. Para edição das imagens uso diversos aplicativos: Snapseed, PicsArt, Câmera Mais, Tadaa, Pic Stitch. Mais recentemente desenvolvi uma nova paixão: o iMovie, um software de edição de vídeos criado pela Apple para os Macs, mas também disponível em seus dispositivos móveis iOS.

Santaella (2016) chamou de "app-learning”, a nova maneira de aprender com os usos dos mais diferentes tipos de aplicativos à disposição de educadores e educandos. Penso que os aplicativos podem e são usados de maneira multi-híbrida e multicombinada quando estamos no campo, no fazer etnográfico e quando já estamos fora do campo, mas em seu continuum. No caminho do que disse Santaella, penso esse modo de etnografar com aplicativos como App-ethnoresearching.

Enfatizamos, e ncerrando provisoriamente essa conversa, que nos inspiram os diálogos que podemos ampliar com Santos (2014), a respeito do diário on-line. Em 2012, criei uma página no Facebook com o nome de "Educação nos terreiros" (título do livro que publiquei no mesmo ano). O objetivo era compartilhar falas e fotografias de crianças de diversos terreiros pelo Brasil, notas e impressões. A página, que atualmente chamo de “Crianças de terreiros: Fotoetnografia Miúda”, é meu fotoetnocaedrno compartilhadoe tem, no momento, mais de 17 mil, não apenas seguidores, mas imaginantes (SANT’ANNA; CAPUTO, 2018) que nela interagem com frequência, incluindo familiares das crianças de terreiros.

A página no Facebook referida pode ser identificada como um jornal de pesquisa (VELOSO, 2017), se preferirem e acharem adequado e acho que se insira nessa abordagem. Contudo, por enquanto, continu- 
arei disponibilizando-a como um fotoetonocarderno compartilhado. É fotoetnocaderno porque mobiliza a fotografia (móvel ou imóvel) com crianças na etnografia e nas autorreflexões de nosso próprio fazer etnográfico. É compartilhado porque, desde o início, disponibilizamos publicamente o que fazemos para oportunizar o debate entre os sujeitos dos terreiros. Novas criações, desafios e dilemas, como sempre.

\section{REFERÊNCIAS}

AMARAL, M. M.; SANTOS, R.; SANTOS, E. Letramentos digitais: o cinema como dispositivo didáticopedagógico potencializador de atos de currículo, no ensino superior. C\&S, São Bernardo do Campo, v. 41, n. 1, p. 159-190, jan.-abr. 2019.

ARDOINO, J. Para uma pedagogia socialista. Brasília: Editora Plano, 2003.

BÂ, A. H. A tradição viva. In: História geral da África. Volume 1. São Paulo, Unesco; Cortez, 2010.

CAPUTO, S. G. Educação em terreiros de candomblé: contribuição para uma educação multicultural crítica. In: CANDAU, V. M. (Org.). Educação Intercultural e cotidiano escolar. Rio de Janeiro: 7 Letras, 2006.

CAPUTO, S. G. Educação nos terreiros: e como a escola se relaciona com crianças de candomblé. Rio de Janeiro: Pallas, 2012.

CAPUTO, S. G. Pesquisar com crianças em terreiros: diálogos e alianças necessárias. In: CANDAU, V. M. (Org.). Interculturalizar, descolonizar, democratizar: uma educação "outra”? Rio de Janeiro: 7 Letras, 2016.

CORSARO, W. A. Sociologia da infância. Porto Alegre: Artmed, 2011.

GOLDMAN, M. A tristeza dos trópicos. Jornal de Resenhas, São Paulo: Discurso Editorial, 1998.

COUTO, E.; PORTO, C.; SANTOS, E. (Org.). APP-Learning - experiências de pesquisa e formação. Salvador: Edufba, 2016.

HIRSCHFELD, L. A. Why don't anthropologists like children. American Anthropologist, 2002.

JAGUN, M. Orí: a cabeça como divindade. Rio de Janeiro: LITTERIS, 2015.

JAGUN, M. Vocabulário temático do candomblé. Rio de Janeiro: LITTERIS, 2017.

Interfaces Científicas • Aracaju • V.8 • N.3 • p. 83 - 98 • $2020 \cdot$ Fluxo Contínuo 
MALINOWSKI, B. K. Os argonautas do Pacífico Ocidental. São Paulo: Abril Cultural, 1978. Coleção Os pensadores.

PESSOA DE BARROS, J. F. A. Floresta sagrada de Ossaim: o segredo das folhas. Rio de Janeiro: Pallas, 2011. ROSA, G. No urubuquaquá no pinhém. Rio de Janeiro: Nova Fronteira, 1984.

SANTAELLA, L. App-Learning e a imaginação criativa a serviço da educação. In:

SANTAELLA, L. Navegar no ciberespaço. 0 perfil cognitivo do leitor imersivo. São Paulo: Paulus, 2004.

SANTAELLA, L. Linguagens líquidas na era da mobilidade. São Paulo: Paulus, 2007.

SANTAELLA, L. A ecologia pluralista da comunicação. Conectividade, mobilidade, ubiquidade. São Paulo: Paulus, 2010

SANTOS, B. S. Para uma pedagogia do conflito. In: SILVA, L. H.; AZEVEDO, J.; SANTOS, E. (Org.).

Reestruturação curricular: novos mapas culturais. novas perspectivas educacionais. Porto Alegre: Sulina, 1996.

SANTOS, E. (Org.). Diário online: dispositivo multirreferencial de pesquisa formação na cibercultura. Portugal: Whitebooks, 2014.

SANTOS, J. E. Os nagôs e a morte. Petrópolis: Vozes, 1986.

SARMENTO, M.; GOUVEA, M. C. S. Estudos da infância, educação e práticas Sociais. Petrópolis: Vozes, 2008.

SANT’ANNA, C.; CAPUTO, S. Ninguém é seguido, somos todos imaginantes. In: Educação, comunicação, cultura e diferença. Vitória: Pedregulho, 2018.

SILVA, V. G. Nos bastidores da pesquisa de campo. Jornal da Tarde, 13 de setembro de 1997.

VELOSO, M. M. S. A.; BONILLA, M. H. O jornal de pesquisa e o diário de campo como dispositivos da pesquisaformação. Interfaces Científicas, v. 6, n. 1, Aracaju: EDUNIT, 2017 
*Texto produzido no Contexto do Programa de Internacionalização CAPES/PRINT, enquanto a autora atuava como bolsista professora visitante sênior, no Instituto de Educação da Universidade do Minho, Braga, Portugal.

\section{(). (1) (-)}

Este artigo é licenciado na modalidade acesso abertosob a Atribuição-Compartilhalgual CC BY-SA

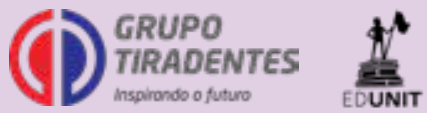

